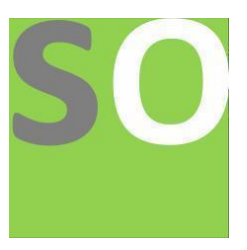

Article title: Evaluation of the Effect of Anatolian Propolis on Covid-19 in Healthcare Professionals: Effect of Anatolian Propolis on Covid-19

Authors: Ozlem Bilir[1], enes guler[2], Abdullah Osman Kocak[3], Ismail Atas[4]

Affiliations: RTE University Training and Research Hospital, Emergency Medicine Department, RIZE[1], Ataturk University Faculty of Medicine, Emergency Medicine Department, ERZURUM[2]

Orcid ids: 0000-0003-4926-0332[2]

Contact e-mail: drenesguler@gmail.com

License information: This work has been published open access under Creative Commons Attribution License http://creativecommons.org/licenses/by/4.0/, which permits unrestricted use, distribution, and reproduction in any medium, provided the original work is properly cited. Conditions, terms of use and publishing policy can be found at https://www.scienceopen.com/.

Preprint statement: This article is a preprint and has not been peer-reviewed, under consideration and submitted to ScienceOpen Preprints for open peer review.

Funder: No funding to declare.

DOI: 10.14293/S2199-1006.1.SOR-.PPZR1OD.v1

Preprint first posted online: 21 October 2021

Keywords: Anatolian propolis, immunity, COVID-19, infection, coronavirus 


\title{
Evaluation of the Effect of Anatolian Propolis on Covid-19 in Healthcare Professionals
}

\author{
Ozlem BILIR ${ }^{1}$, Enes GULER ${ }^{2 *}$, Abdullah Osman KOCAK ${ }^{3}$, Ismail Atas ${ }^{4}$ \\ ${ }^{1}$ RTE University Training and Research Hospital, Emergency Medicine Department, RİZE \\ ${ }^{2}$ RTE University Training and Research Hospital, Emergency Medicine Department, RİZE \\ ${ }^{3}$ Ataturk University Faculty of Medicine, Emergency Medicine Department, ERZURUM \\ ${ }^{4}$ RTE University Training and Research Hospital, Emergency Medicine Department, RİZE \\ *Corresponding author \\ E-mail of the corresponding author: drenesguler@gmail.com
}

\begin{abstract}
Background: No prophylactic treatment is available for individuals at high risk of developing COVID-19. This study, which was conducted between December 25, 2020 and January 25, 2021, is one of the first clinical studies to evaluate the efficacy of Anatolian propolis supplement against COVID-19. The aim was to obtain evidence on the prophylactic use of Anatolian propolis in individuals at high risk of developing COVID-19.

Methods: This volunteer-based study was conducted in two centers. Study involved 209 healthcare professionals (physicians, nurses, medical secretaries) from Emergency Medicine Department of Medical Faculty of Ataturk University and Emergency Medicine Department of Rize Recep Tayyip Erdogan University. 209 participants meeting the study criteria were divided into two groups as experimental group and control group. The experimental group received 20 drops of BEE'O UP 30\% Propolis Drops twice a day during a follow-up period of 1 month. The control group received no supplement but was followed up.

Findings: The participants showing symptoms during the study and all the participants at the end the study were subjected to PCR testing. The evaluation of the results of PCR testing at the end of the study has shown that 14 participants from the control group and only 2 participants from the experimental group, who received Anatolian propolis supplement, were reported as positive cases.
\end{abstract}

Interpretation: It has been found that a statistically significant protection was induced against COVID-19 infection in $98 \%$ of the experimental group, who received Anatolian propolis, compared to the control group.

Funding: No funding to declare.

Registration: URL: https://www.clinicaltrials.gov; Unique identifier: NCT04680819

Keywords: Anatolian propolis, immunity, COVID-19, infection, coronavirus 


\section{INTRODUCTION}

Severe Acute Respiratory Syndrome (SARS), known as Coronavirus (SARS-CoV-2), the first cases of which were reported on December 31, 2019 in Wuhan city of Hubei province in China, has become a pandemic, which continues to spread rapidly across the world and threatens public health. According to the data of World Health Organization (WHO), global coronavirus cases exceeded 230 million, and more than 4.7 million people died during this pandemic (1). With an incubation period of 2-14 days and developing with symptoms such as muscle pain, dry cough, fever and difficulty in breathing, has been reported as a lower respiratory tract infection affecting other organ systems (2). In most of the cases, the infection is mild and may progress to pneumonia, acute respiratory distress syndrome and multiple organ failure in elderly (>50 years old) patients and patients with cardiac and respiratory disorders (3).

Many healthcare professionals were diagnosed with COVID-19 following the pandemic announcement of the World Health Organization on March 10, 2020 and after the first cases were reported on March 11, 2020 in Turkey. By April 2020, 7,428 healthcare professionals were diagnosed with COVID-19 in Turkey, accounting for approximately $6.5 \%$ of all the cases. In December 2020, the number of healthcare professionals, who tested positive for COVID-19, was more than 120,000. Since the beginning of the pandemic, the number of cases in our country has exceeded 6.6 million, and more than 59 thousand people have died (4). Although medications such as hydroxychloroquine, azithromycin, favipiravir, remdesivir and lopinavir/ritonavir are used for the treatment of this infection with acute respiratory failure and organ dysfunctioning, a specific antiviral treatment has not yet been identified. The clinical studies on the efficacy of these medications are still ongoing. In the world of science, the researches on development of virus-specific antiviral still continue. The supportive treatments for COVID-19, which are applied in our country, include corticosteroid therapy, immune plasma administration and alternative therapies $(4,5)$.

Diet, infections and the immune system are directly associated with each other. A sufficient and balanced diet is important for keeping the immunity mechanisms strong throughout life. Enriching the diet with natural food supplements is also effective in regulation of the immune response. In our diet, some nutrients act on production of immune system cells, while some act as antioxidants and play a role in the regulation of immune system functions and inflammatory response. Individuals, who want to speed up the healing process of the infection or to be protected during the pandemic, have turned towards natural food supplements. Anatolian propolis is one of the primary natural food supplements used as immune supplement during the COVID-19 pandemic $(6,7)$.

Propolis is a completely natural bee product with strong antioxidant, anti-inflammatory, antiviral and antimicrobial activity, which bees collect from the leaves, stems and buds of plants. It is used by bees to destroy the microbes and sterilize the hives. Firstly, bees cover the cells of the honeycomb with propolis, and then the queen lays her eggs in the cells. This ensures healthy development of the egg. In addition, bees put honey, pollen and royal jelly in the cells of the honeycomb, which is covered with propolis. In this way, the bee products are kept intact in the hive. The nutrient composition of propolis includes phenolic and flavonoid components, minerals, polysaccharides, amino acids, amines and amides. Propolis is not suitable for the human digestive system in its raw form with beeswax. Its bioavailability in the human body is $2 \%$. It must undergo an extraction process and the wax contained in it must be removed through a suitable technology in order to benefit from the rich nutritional composition and health effects of propolis. This extraction process is performed with glycol and ethyl alcohol. Propolis provides antioxidant effect with the phenolic and flavonoid components contained in it. The scientific studies conducted report that propolis, which is a natural immune supplement, has positive effects when used to support the treatment of various diseases such as respiratory tract diseases, gastrointestinal disorders, oral aphthae, mouth sores and herpes, diabetes and cancer (8).

Functional foods are an interesting concern for boosting the immune response, especially in the elderly, immunocompromised populations with viral infections. Scientific researches on the chemical interactions, which may occur between certain food compounds and host or virus targets, are still ongoing to interfere with the COVID-19 (SARS-CoV-2) viral infection cycle. It is known that natural bee products support the immune system by playing role in induction of antibody production, maturation of immune cells, and stimulation of innate and adaptive immune responses. In the absence of specific antiviral agents against COVID-19, natural bee 
products have been said to be promising (9). Propolis is one of these bee products with its high antioxidant capacity and antiviral activity. The recent scientific publications report that propolis must be investigated as a prophylaxis in the groups at high risk of developing COVID-19. It is noted that the biological activities and mechanisms of action of the compounds naturally found in propolis must be determined in vitro and in vivo. In accordance with these studies, isolation of propolis components with high antiviral activity and their use as treatment supporting agents must be ensured (10).

Polyphenols are a large family of more than 10,000 naturally occurring compounds that offer countless pharmacological, biological and physiological benefits for human health. The scientific studies conducted have proven that polyphenols are components enabling enhancement of the host immune response against viral infections such as SARS and MERS, which are quite similar to COVID-19. Therefore, the current literature suggests that polyphenols such as quercetin, resveratrol, caffeic acid, coumaric acid, chrysin and apigenin must be considered in pharmacological treatment methods, which can be used effectively in the fight against COVID19 and other viral diseases (11).

The entry of SARS-CoV-2 into host cells is characterized by interaction of viral spike protein with cellular angiotensin converting enzyme 2 (ACE2) and the serine protease TMPRSS2. This mechanism leads to overexpression of PAK1, resulting in lung inflammation, fibrosis, and suppression of the immune response. PAK1 (RAC/CDC42-activated kinase 1) is the major "pathogenic" kinase, the abnormal activation of which results in various diseases/disorders including cancers, inflammation, malaria and influenza, HIV and COVID-19 (12). Propolis components have inhibitory effects on the ACE2, TMPRSS2 and PAK1 signaling pathways. The pre-clinical studies have also proven that propolis supports immunoregulation of pro-inflammatory cytokines, including reduction in IL-6, IL-1 beta and TNF $\alpha$. This immunoregulation involves monocytes and macrophages, as well as Jak2/STAT3, NF-kB and inflammatory pathways, and reduces the risk of cytokine storm syndrome, which is a major mortality factor in COVID-19 infection (13).

Different in silico and in vitro studies have demonstrated that the molecules belonging to the polyphenol family can interfere with various stages of the entry and replication cycle of coronavirus. Flavonoids such as quercetin, baicalin, luteolin, hesperetin, gallocatechin gallate and epigallocatechin gallate, and their secondary metabolites have been shown to be able to inhibit key proteins involved in the coronavirus infective cycle such as PLpro, 3CLpro, and NTPase/helicase.

In vitro and in silico studies show that phenolic compounds such as caffeic acid phenethyl ester, caffeic acid, chrysin, galangin, resveratrol, quercetin, catechin and hesperidin can be used as supportive agents in the prevention and treatment of COVID-19 (15). A recent in vitro study has shown that the caffeic acid compound has powerful antagonist activity against human coronavirus ( $\mathrm{HCoV})$ NL63 by inhibiting the interaction of the virus with the ACE2 receptor (16). The potential antagonistic activity of caffeic acid toward SARS-CoV-2 has been highlighted in a recent molecular-docking study, where the binding capacities of some propolis compounds against the Mpro virus were investigated. In this study, caffeic acid phenethyl ester has been reported to have a good affinity for the active site of the enzyme and be a potential virus antagonist. The same study has defined chrysin and galangin, which are other propolis polyphenolic compounds, as potential anti-SARS-CoV-2 agents (17).

In the clinical studies conducted, it is seen that propolis is an effective antiviral and antibacterial agent. In a double-blind, placebo-controlled clinical study conducted by Esposito et al., it has been shown that oral propolis supplementation improved the symptoms of mild upper respiratory tract infection without requiring pharmacological treatment (18).

In a randomized clinical study, where the effects of treatment by syrup containing propolis and henbane (Hyoscyamus niger L.) were observed, it has been found to be effective in COVID-19 patients in reduction of the symptoms such as dry cough, difficulty in breathing, sore throat, chest pain, fever, dizziness, headache, abdominal pain and diarrhea (19).

The antiviral effect of propolis against COVID-19 acts through two mechanisms, which are boosting the immune response against SARS-CoV-2 and acting on viral RNA. The studies have shown that the modulation of 
extracellular signal-regulated kinase-2 and MAPK signaling pathway is mediated by propolis, and that it has an immunomodulatory effect. In addition, propolis stimulates production of excess antibodies, which suggests that it can be used as an adjuvant in the vaccines. The researchers report that propolis can be tried as a prophylactic supplement against COVID-19 due to its immunomodulatory and antiviral effects $(20,21)$.

\section{MATERIAL AND METHOD}

This is an observational prophylaxis study (URL: https://www.clinicaltrials.gov; Unique identifier: NCT04680819), which was conducted between December 25, 2020 and January 25, 2021 in order to evaluate the effect of Anatolian propolis supplement administered to healthcare professionals in emergency department, who are at high risk of developing COVID-19, on the development of infection. The subjects consisted of 209 healthcare professionals (physicians, nurses, medical secretaries) from Emergency Medicine Department of Medical Faculty of Atatürk University and Emergency Medicine Department of Rize Recep Tayyip Erdogan University, who met the study criteria. It was a volunteer-based study, and conducted with 63 female and 146 male healthy individuals aged between 18-65. The participants signed a voluntary participation form prior to the study. The inclusion and exclusion criteria for the study were as follows:

\section{Criteria for Inclusion in the Study:}

- $\quad$ Being an adult aged between 18-65

- Being a volunteer participant

- Having no chronic diseases

- $\quad$ Not being diagnosed with COVID-19 (diagnosed by PCR testing)

- Having experienced COVID-19 symptoms in the last 14 days (fever, fatigue, loss of taste and smell)

- Serving as a healthcare professional in an emergency department (physician, nurse, medical secretary)

\section{Criteria for Exclusion from the Study}

- $\quad$ Age under 18

- Not to be volunteer to participate in the study

- Pregnancy

- Having an immunosuppressive disease

- Receiving chemotherapy treatment

- Having allergy or hypersensitivity to propolis

- Receiving medication,

- To be assigned to another department from the emergency department within a period of 1 month, which is planned as the study period

Five participants, who did not meet the inclusion criteria, were excluded from the study. One of the participants excluded from the study had an allergic reaction, while the other 4 did not comply with the study. The volunteer participants were divided into two groups as experimental group and control group, each consisting of 102 people. The experimental group consisted of 102 people and received 20 drops of BEE'O UP 30\% Propolis Drops twice a day, in the morning and evening, during a follow-up period of 1 month. The control group consisted of 102 people and received no supplement. As a control and reminder, it has been confirmed by the call center whether the participants in the study group receiving BEE'O UP 30\% Propolis drops took the drops or not. During the study, the participants were followed up for a period of 1 month, and the individuals, who were tested PCR positive and diagnosed with COVID-19, were recorded. At the end of 1 month, which was the end of the study, the rates of the participants, who were diagnosed with COVID-19 based on the results of PCR testing, from the study group and control group were compared. Based on the results, it was determined whether Anatolian propolis is protective against COVID-19 or not. Registration: URL: https://www.clinicaltrials.gov; Unique identifier: NCT04680819. 


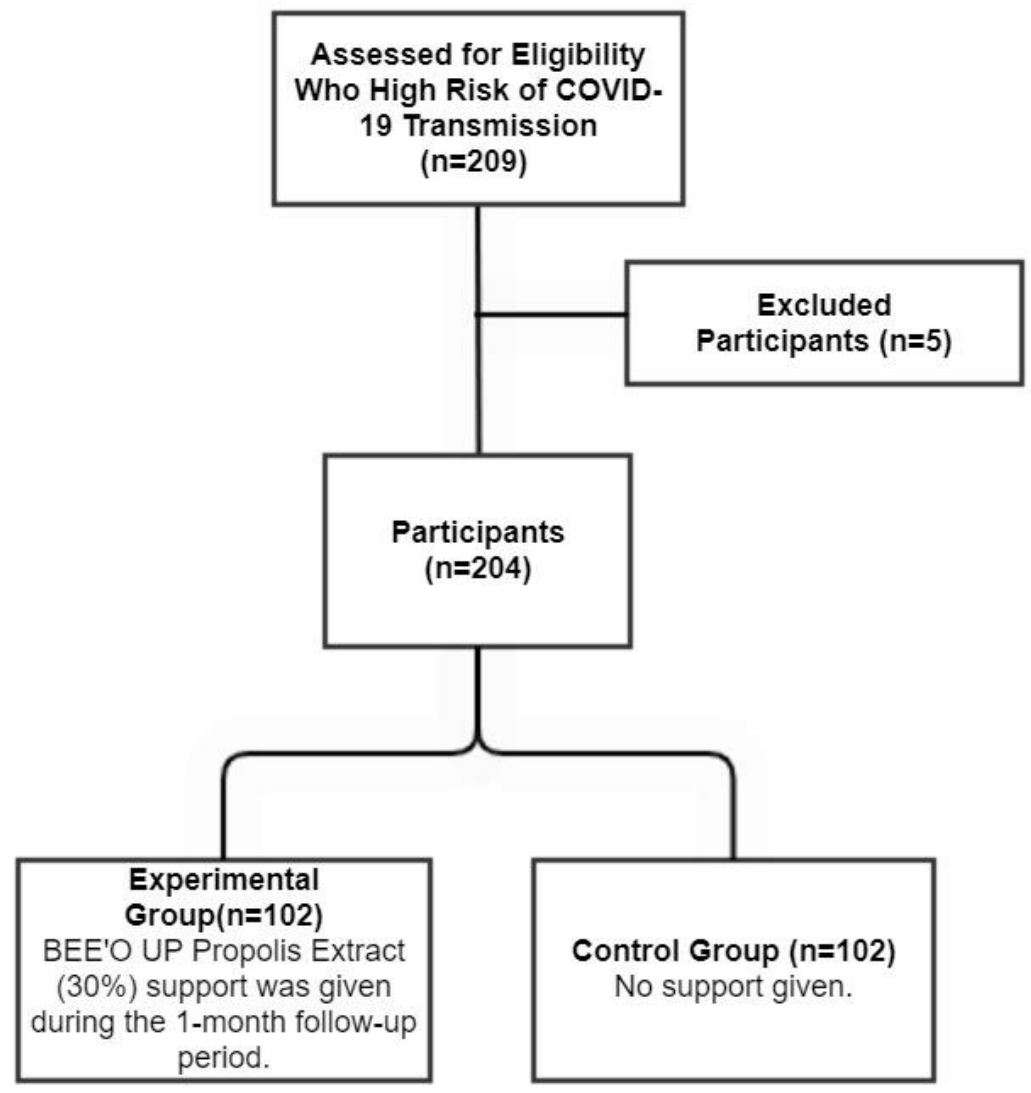

Figure 1. Study Diagram

\section{Preparation of Anatolian Propolis Extract}

The production of BEE'O UP Propolis Drops took place through the innovation-award winner and patented extraction technology developed in ARI Teknokent laboratories of Istanbul Technical University. Based on the spectrophotometric analysis report of this product, the minimum phenolic content per $\mathrm{ml}$ is $106.0 \mathrm{mg} \mathrm{GAE}$, the flavonoid content is $73.1 \mathrm{mg}$ ke and the total content is $253.9 \mathrm{mg}$ te/ml.

\section{Total Phenolic Content of BEE'O UP Propolis Drops (30\%)}

Based on the results of the analysis performed on 10.06.2020 in the R\&D Laboratory of SBS Scientific Bio Solutions and the Chemistry Department Laboratory of Science Faculty of Karadeniz Technical University, the phenolic and flavonoid component content of BEE'O UP Propolis Drops (30\%) is as follows.

Table 1. Analysis Results of BEE'O UP Propolis Drops (30\%)

\begin{tabular}{|l|l|}
\hline Content Information Declared on the Label & $\begin{array}{l}\text { Pure Anatolian Propolis (30\%), } \\
\text { Water-ethanol solution }\end{array}$ \\
\hline pH & $5.10 \pm 0.02$ \\
\hline Total Polyphenol Content $(\mathbf{m g ~ G A} / \mathbf{m l})$ & $59.3 \pm 0.93$ \\
\hline Total Flavonoid Content $(\mathbf{m g ~ G A} / \mathbf{m l})$ & $22.3 \pm 0.23$ \\
\hline Total Antioxidant Capacity (FRAP mmol FeSO $\left.\mathbf{4}_{\mathbf{4}} \mathbf{7} \mathbf{H}_{\mathbf{2}} \mathbf{O} / \mathbf{m l}\right)$ & $858.9 \pm 0.74$ \\
\hline Analysis Results of Phenolic Component & Results $(\mathbf{m c g} / \mathbf{m l ~ s a m p l e )}$ \\
\hline p-Hydroxybenzoic acid & 143.0 \\
\hline Epicatechin & 312.0 \\
\hline Caffeic acid & 1520.0 \\
\hline
\end{tabular}




\begin{tabular}{|l|l|}
\hline p-Coumaric acid, & 406.8 \\
\hline Ferulic acid & 977.2 \\
\hline Resveratrol & 45.3 \\
\hline Luteolin & 38.7 \\
\hline Quercetin & 186.3 \\
\hline t-Cinnamic acid & 158.8 \\
\hline Apigenin & 451.2 \\
\hline Hesperetin & 384.8 \\
\hline Rhamnetin & 610.0 \\
\hline Chrysin & 5942.0 \\
\hline Pinocembrin & 1036.2 \\
\hline Caffeic acid phenethyl ester (CAPE) & 16792.0 \\
\hline
\end{tabular}

\section{Statistical Analysis of Study Data}

Statistical analysis of the study data was performed by the software SPSS.20. Data were evaluated in percentages and numbers. Shapiro-Wilk and Kolmogorov-Smirnov tests were used to evaluate whether it complied with the normal distribution or not. Independent samples t-test was used to compare normally distributed data between two independent groups. Categorical variables were compared using Chi-square and Fisher tests. $\mathrm{P}<0,05$ was considered statistically significant.

\section{FINDINGS}

Among the healthcare professionals participating in the study, the mean age of the group, who received Anatolian propolis supplement, was $35.21 \pm 7.27$ years, while the mean age of the control group was $33.80 \pm$ 6.22 years. The mean height of the group, who received Anatolian propolis supplement, was $173.26 \pm 6.13 \mathrm{~cm}$, while the mean height of the control group was $171.94 \pm 5.56 \mathrm{~cm}$. The mean weight of the group, who received Anatolian propolis supplement, was 70,92 $\pm 7,48 \mathrm{~kg}$, while the mean weight of the control group was 70,02 \pm $6,72 \mathrm{~kg}$. The mean Body Mass Index of the group, who received Anatolian propolis supplement, was 23,58 \pm $2,03 \mathrm{~kg} / \mathrm{m}^{2}$, while the mean Body Mass Index of the control group was $23,65 \pm 1,94 \mathrm{~kg} / \mathrm{m}^{2}$.

Table 2. Demographic Information of Study Participants

\begin{tabular}{|l|l|l|l|}
\hline Variable & Propolis & Control & P Value \\
\hline Age & $35.21 \pm 7.27$ & $33.80 \pm 6.22$ & 0.141 \\
\hline Gender & & & 0.879 \\
\hline Height & $173.26 \pm 6.13$ & $171.94 \pm 5.56$ & 0.108 \\
\hline Weight & $70.92 \pm 7.48$ & $70.02 \pm 6.72$ & 0.366 \\
\hline Body Mass Index (BMI) & $23.58 \pm 2.03$ & $23.65 \pm 1.94$ & 0.781 \\
\hline
\end{tabular}

The evaluation of the results of PCR testing of all the participants at the end of the study has shown that 14 participants from the control group and only 2 participants from the experimental group, who received Anatolian propolis supplement, were reported as positive cases. Anatolian propolis supplement has been found to provide statistically significant protection of approximately $98 \%$.

\section{DISCUSSION}

Recently published scientific studies show that propolis has positive effects on the development mechanisms of coronavirus, and that the immune response as a result of the hyperactivation of the immune system, which is called the cytokine storm and observed during the coronavirus infection. The researchers report that the polyphenolic components in the composition of propolis balance the immune response by suppressing the cytokine storm. With its rich polyphenol profile, propolis is a promising natural food supplement, which can be used in the treatment of COVID-19. 
In the light of the information on the viral targets in the transmission of COVID-19, there is not yet a more protective alternative than the vaccine against the spread of infection. The interaction of viral spike protein with cellular angiotensin converting enzyme 2 (ACE2) and human transmembrane protease TMPRSS2 plays a role in the virulence of COVID-19.

Anatolian geography is rich in the diversity of endemic flora due to its location. The bee products obtained from this region are also of high quality and have nutritional content. The results of analysis on antioxidant capacity and phenolic and flavonoid content have shown that Anatolian propolis contains 15 different phenolic and flavonoid components. These components are Caffeic Acid Phenethyl Ester (CAPE), Caffeic Acid, Quercetin, Galangin, Chlorogenic acid, Linolenic acid, Palmitic acid, Hydroxytyrosol, Coumaric acid, Apigenin, Chrysin and Pinocembrin. The rich polyphenol content of Anatolian propolis has been confirmed by this analysis report. The total antioxidant capacity was found to be $858,9 \pm 0,74$ FRAP mmol $\mathrm{FeSO}_{4} .7 \mathrm{H}_{2} \mathrm{O} / \mathrm{ml}(22)$.

The scientific studies conducted have shown that the use of Anatolian propolis to support the treatment of recurrent respiratory tract infections, urinary system infections, gastrointestinal diseases, wounds and burns, cancer, diabetes and finally COVID-19 ensures significant benefits.

There are some preclinical data regarding that propolis components are able to inhibit and/or modulate the viral targets. The studies provided data showing that Anatolian propolis is able to inhibit the targets, which determines the virulence of COVID-19. In the research conducted at Karadeniz Technical University in 2021 by molecular modeling method, the effects of naturally occurring phenolic and flavonoid components contained in Anatolian Propolis against coronavirus infection were evaluated. The flavonoids naturally found in Anatolian propolis (Caffeic Acid Phenethyl Ester (CAPE), hesperetin, caffeic acid, quercetin, pinocembrin, galangin) have been found to exert an inhibitory effect on the binding of the virus spike S1 protein, which acts on transmission and spread of the SARS-CoV-2 virus, and the ACE-2 receptor from the host cell receptors. The findings of the study show that Anatolian propolis has a high inhibitory potential against COVID-19 (23).

This study was designed to evaluate the effects of Anatolian propolis on healthcare professionals, who have been at the forefront of the fight against COVID-19 infection and are among the highest groups, and to obtain evidence for its use for prophylaxis.

In a case report published in Acta Medica Mediterranae in April 2021, the use of BEE'O UP branded Anatolian propolis in addition to the medical treatment of a 38-year-old patient, who tested corona positive, and its effect on the course of the disease have been shown. Evaluation of the case report has shown that daily supplementation of 20-80 drops of BEE'O UP Anatolian Propolis in addition to the current medical treatment of coronavirus provides highly significant results in the complete regression of the pulmonary findings and difficulty breathing recovery of the patient (24).

In the study, where the effect of Anatolian propolis against SARS-coronavirus-2 (SARS-CoV-2) was investigated in vitro and in silico, pinocembrin, one of the phenolic components contained in propolis, has been found to have the highest potential of binding to virus spike 1 protein. It is followed by chrysin, Caffeic Acid Phenethyl Ester (CAPE) and hesperetin. The findings of two studies have shown that propolis has a high inhibitory potential against COVID-19 virus (25).

In parallel with other scientific researches, this study has also concluded that Anatolian propolis supplement is an effective therapeutic agent in the fight against COVID-19 infection. Additional clinical studies are required for new SARS-CoV-2 variants, which have emerged after the study was conducted.

\section{CONCLUSION}

With its rich endemic flora diversity, Anatolian geography offers bee products of high quality. Anatolian propolis is also one of the natural bee products with a strong polyphenol profile. Compared to other propolis extracts, Anatolian propolis provides richer phenolic and flavonoid content. In addition, the studies conducted on Anatolian propolis have shown that it has positive effects on many health problems. In the prophylaxis study conducted, Anatolian propolis supplementation has been found to reduce the possibility of COVID-19 transmission among healthcare professionals, who are in the high risk group. It has been found that a statistically 
significant protection was induced against COVID-19 infection in 98\% of the experimental group, who received Anatolian propolis, when compared to the control group. It has been reported that Anatolian propolis can be an effective supplement to help reduce the morbidity and mortality of the COVID-19 pandemic.

\section{Study Restrictions}

Since administration of vaccination against COVID-19 started shortly after the start of the study, the duration of study was determined as 1 month. In order to prevent vaccination administration becoming confounding factor, the study discontinued.

\section{REFERENCES}

1. WHO Coronavirus (COVID-19) Dashboard. https://covid19.who.int/ 28.09.2021.

2. Huang, C., Wang, Y., Li, X., Ren, L., Zhao, J., Hu, Y., ... \& Cao, B. (2020). Clinical features of patients infected with 2019 novel coronavirus in Wuhan, China. The lancet, 395(10223), 497-506.

3. Sharma, Atul, et al. "Severe acute respiratory syndrome coronavirus-2 (SARS-CoV-2): a global pandemic and treatment strategies." International journal of antimicrobial agents 56.2 (2020): 106054

4. T.C. Sağlık Bakanlığ1 COVID-19 Bilgilendirme Platformu. https://covid19.saglik.gov.tr/ 28.09.2021.

5. MUTLU, O., UYGUN, İ., \& ERDEN, F. (2020). Koronavirüs Hastalı̆̆1 (COVID-19) Tedavisinde Kullanılan İlaçlar. Kocaeli Üniversitesi Sağlı Bilimleri Dergisi, 6(3), 167-173.

6. DAZIROĞLU, M. E. Ç., YILDIZ, M., \& AKBULUT, G. COVID-19 Pandemisine Diyetetik Bakış: Besin, Besin Destekleri ve Tıbbi Beslenme Tedavisi. ERÜ Sağlık Bilimleri Fakültesi Dergisi, 8(1), 1322.

7. Yasar, R. K., \& Aytekin, Ö. Ü. (2021). COVID-19 ve Beslenme Arasındaki İlişkiye Güncel Bir Bakış. Akademik Glda, 19(1), 108-115.

8. Braakhuis, Andrea. "Evidence on the health benefits of supplemental propolis." Nutrients 11.11 (2019): 2705.

9. Lima, W. G., Brito, J. C., \& da Cruz Nizer, W. S. (2021). Bee products as a source of promising therapeutic and chemoprophylaxis strategies against COVID-19 (SARS-CoV-2). Phytotherapy Research, 35(2), 743-750.

10. Bachevski, D., Damevska, K., Simeonovski, V., \& Dimova, M. (2020). Back to the basics: Propolis and COVID-19. Dermatologic Therapy, 33(4), e13780.

11. Khalil, A., \& Tazeddinova, D. (2020). The upshot of Polyphenolic compounds on immunity amid COVID-19 pandemic and other emerging communicable diseases: An appraisal. Natural Products and Bioprospecting, 1-19.

12. Maruta, H., \& He, H. (2020). PAK1-blockers: Potential Therapeutics against COVID-19. Medicine in drug discovery, 6, 100039.

13. Berretta, A. A., Silveira, M. A. D., Capcha, J. M. C., \& De Jong, D. (2020). Propolis and its potential against SARS-CoV-2 infection mechanisms and COVID-19 disease. Biomedicine \& Pharmacotherapy, 110622

14. Russo, M., Moccia, S., Spagnuolo, C., Tedesco, I., \& Russo, G. L. (2020). Roles of flavonoids against coronavirus infection. Chemico-biological interactions, 109211.

15. Di Matteo, G., Spano, M., Grosso, M., Salvo, A., Ingallina, C., Russo, M., ... \& Mannina, L. (2020). Food and COVID-19: preventive/co-therapeutic strategies explored by current clinical trials and in silico studies. Foods, 9(8), 1036.

16. Weng, J. R., Lin, C. S., Lai, H. C., Lin, Y. P., Wang, C. Y., Tsai, Y. C., ... \& Lin, C. W. (2019). Antiviral activity of Sambucus FormosanaNakai ethanol extract and related phenolic acid constituents against human coronavirus NL63. Virus research, 273, 197767.

17. Hashem, H. (2020). In Silico approach of some selected honey constituents as SARS-CoV-2 main protease (COVID-19) inhibitors.

18. Esposito, C., Garzarella, E. U., Bocchino, B., D'Avino, M., Caruso, G., Buonomo, A. R., ... \& Daglia, M. (2021). A standardized polyphenol mixture extracted from poplar-type propolis for remission of symptoms of uncomplicated upper respiratory tract infection (URTI): A monocentric, randomized, double-blind, placebo-controlled clinical trial. Phytomedicine, 80, 153368. 
19. Kosari, M., Noureddini, M., Khamechi, S. P., Najafi, A., Ghaderi, A., Sehat, M., \& Banafshe, H. R. (2021). The effect of propolis plus Hyoscyamus niger L. methanolic extract on clinical symptoms in patients with acute respiratory syndrome suspected to COVID-19: A clinical trial. Phytotherapy Research.

20. Mrityunjaya, M., Pavithra, V., Neelam, R., Janhavi, P., Halami, P. M., \& Ravindra, P. V. (2020). Immune-boosting, antioxidant and anti-inflammatory food supplements targeting pathogenesis of COVID-19. Frontiers in Immunology, 11.

21. SBS Bilimsel Bio Çözümler San. ve Tic. A.Ş., "BEE’O UP Propolis Damla (\%30) Analiz Sonuçları”, Karadeniz Teknik Üniversitesi, 2020.

22. Mohamed, S. S. E. (2020). Propolis anti-viral activity towards CODIV-19: is it effective?. Preprint, March.

23. Guler, H. I., Tatar, G., Yildiz, O., Belduz, A. O., \& Kolayli, S. (2021). Investigation of potential inhibitor properties of ethanolic propolis extracts against ACE-II receptors for COVID-19 treatment by Molecular Docking Study. Archives of microbiology, 1-8.

24. Zorlu, D. U. Y. G. U. (2021). COVID-19 and Anatolian propolis: A case report. Acta Medica Mediterranea, 37(2), 1229-1233.

25. Guler, H. I., Fulya, A. Y., Zehra, C. A. N., Yakup, K. A. R. A., BELDUZ, A. O., CANAKCI, S., \& KOLAYLI, S. (2021). Targeting CoV-2 Spike RBD and ACE-2 Interaction with Flavonoids of Anatolian Propolis by in silico and in vitro Studies in terms of possible COVID-19 therapeutics. bioRxiv. 